\title{
Rail Corrugation Detection of High-Speed Railway Using Wheel Dynamic Responses
}

\author{
Jianbo Li $\mathbb{i D}^{1,2}$ and Hongmei Shi $\mathbb{D}^{1,2}$ \\ ${ }^{1}$ School of Mechanical, Electronic and Control Engineering, Beijing Jiaotong University, Beijing 100044, China \\ ${ }^{2}$ Key Laboratory of Vehicle Advanced Manufacturing, Measuring and Control Technology (Beijing Jiaotong University), \\ Ministry of Education, Beijing 100044, China \\ Correspondence should be addressed to Hongmei Shi; hmshi@bjtu.edu.cn
}

Received 4 January 2019; Accepted 11 February 2019; Published 25 February 2019

Guest Editor: Krzysztof Holak

Copyright (c) 2019 Jianbo Li and Hongmei Shi. This is an open access article distributed under the Creative Commons Attribution License, which permits unrestricted use, distribution, and reproduction in any medium, provided the original work is properly cited.

\begin{abstract}
Rail corrugation often occurs on the high-speed railway, which will affect ride comfort and even the train operation safety in severe condition. Detection of rail corrugation wavelength and depth is absolutely essential for maintenance and safety. A novel method using wheel vibration acceleration is proposed in this paper, in which ensemble empirical mode decomposition (EEMD) is employed to estimate the wavelength, and bispectrum features are extracted to recognize the depth with support vector machine (SVM). Firstly, a vehicle-track coupling model considering the rail corrugation of high-speed railway is established to calculate the wheel vibration acceleration. Secondly, the estimation algorithm of wavelength is studied by analyzing the main frequency with EEMD. The optimal parameters of EEMD are selected according to the orthogonal coefficient of decomposition results and the distribution of the extreme points of signal. The depth detection is transformed to a classification problem with SVM. Bispectrum features, which are extracted from the reconstructed signal using the high-frequency components of wheel vibration acceleration, combining with train speed and corrugation wavelength are input into SVM to recognize the rail corrugation depth. Finally, numerical simulation is carried out to verify the accuracy of the proposed estimation method. The simulation results show that the proposed detection algorithm can accurately identify rail corrugation, the estimation error of rail corrugation wavelength is less than $0.25 \%$, and the classification accuracy of rail corrugation depth is more than $99 \%$.
\end{abstract}

\section{Introduction}

Rail corrugation is a type of wavy wear formed longitudinally along the top of the rail, which appears in all types of rail systems [1]. With the rapid development of high-speed railway, rail corrugation has been found everywhere, especially with a fixed rail corrugation wavelength due to the same train operation speed and vehicle type. The results of field tests on a high-speed railway in China [2] show that rail corrugation is distributed in many discontinuous places. The length of rail corrugation is usually about $10 \mathrm{~m}$ to $15 \mathrm{~m}$ along the longitudinal direction of rail, and the wavelength is from $120 \mathrm{~mm}$ to $150 \mathrm{~mm}$. The depth of rail corrugation is much smaller, generally in the range of $0.04 \mathrm{~mm}$ to $0.1 \mathrm{~mm}$. The rail corrugation causes aggravated interactions between vehicle and rail and terrible noises, which severely influences the safety and ride comfort of a running high-speed train. It is necessary for maintenance and safety to detect the wavelength and depth of rail corrugation effectively.

In recent years, research of track structure health monitoring utilizing vehicle vibration responses has attracted more and more attention. There are many studies on rail corrugation monitoring based on operating vehicles. Rail corrugation detection method based on vehicle vibration responses is a noncontact detection method. Moreover, vibration acceleration signal is easy to obtain, and real-time monitoring of track status can be realized without affecting railway operation. Hopkins and Taheri [3] proposed a defect detection algorithm for rail health monitoring with wavelet transform. The vibration acceleration signal of the bogie is 
decomposed by wavelet transform, and the Lipschitz exponent of each scale is calculated to identify wheel flat, rail crack, and rail corrugation. Molodova et al. [4] used axle box acceleration to measure short wave track defects including rail corrugation. The amplitude and power spectral density of the vibration acceleration signal of axle box are analyzed to detect defects. Huang et al. [5] proposed a rail corrugation detection technology based on fiber laser accelerometer. The fiber laser accelerometer is installed on the bogie to detect the vertical acceleration of train axle box. The vibration acceleration signal is denoised by wavelet transform, and then the waveform of rail corrugation is estimated by double integral. Kaewunruen [6] used dynamic wheel-rail interaction to monitor rail corrugation on curved track for guiding maintenance. Corrugation roughness data are also obtained by double integration of axle box acceleration signals. Salvador et al. [7] made time-frequency analysis of the axle box vibration acceleration signal with short-time Fourier transform, which can detect rail corrugation, isolated rail defects, and loss of track vertical alignment. Most of the above studies only identify if there is rail corrugation defect, without giving a detailed diagnosis of the wavelength and depth of rail corrugation.

EEMD is a signal decomposition method, which is an improvement algorithm of empirical mode decomposition (EMD) and widely used in signal analysis and mechanical fault diagnosis. Shen et al. [8] proposed fast EEMD optimization algorithm, which applies nonlinear correlation coefficient and accuracy requirements to obtain the best parameters of EEMD. The proposed EEMD optimization algorithm is used to extract the accent of emotional speech. Guo and Tse [9] used EEMD to analyze bearing vibration signals and proposed a method to automatically select appropriate EEMD parameters using the relative root mean square error between the decomposition result and the original signal. Xue et al. [10] applied the same method to diagnose the fault of rolling bearing. Kedadouche et al. [11] used the Pearson coefficient of correlation between IMFs to select the parameters of EEMD.

In this paper, a rail corrugation detection method is presented based on the vertical vibration response of wheel. The basic principle of detection algorithm is analyzing the high frequency of wheel vibration acceleration with EEMD method to estimate the wavelength and depth of rail corrugation. The paper is organized as follows: A vehicle-track coupling model considering rail corrugation is described in Section 2 to calculate the wheel vibration acceleration used in the detection algorithm. The detection algorithm of rail corrugation is presented in Section 3, in which the estimation method of wavelength using EEMD to acquire the main frequency and the bispectrum features extraction to classify the depth are, respectively, described in detail. The numerical simulation and detection results of rail corrugation are demonstrated and analyzed in Section 4.

\section{Simulation Model}

In order to obtain the wheel dynamic responses used to detect rail corrugation, a vertical vehicle-track coupling model is established as shown in Figure 1, consisting of vehicle model, track model, track irregularity model, and rail corrugation model.

2.1. Vehicle Model of High-Speed Railway. The vehicle model is a multibody system including a car body, two bogies, and four wheelsets, which are connected by stiffness-damping elements [12]. There are 10 degrees of freedom, which are the vertical motion $y_{c}$ and nodding motion $\beta_{c}$ of the car body, the vertical motion $y_{t}$ and nodding motion $\beta_{t}$ of two bogies, and the vertical motion $y_{w}$ of four wheelsets. The vehicle parameters of Chinese high-speed train CRH3 used in the model are represented in Table 1.

2.2. Slab Track Model. The slab ballastless track structure is applied into the track model for its wide use in China highspeed railway, which is constituted of rail, fasteners, track slabs, CA mortar layer, and foundation [14]. The rail is regarded as an infinite beam with continuous support, the track slab is regarded as a free beam, and the fasteners and mortar layer are represented as equivalent stiffness-damping elements. The parameters of the slab track model for simulation are shown in Table 2.

2.3. Vehicle-Track Coupling Model. The vehicle model and the track model are coupled by wheel-rail interaction. According to Hertzian nonlinear elastic theory [12], the vertical force between the wheel and rail is defined as

$$
p(t)= \begin{cases}{\left[\frac{1}{G} \Delta Z(t)\right]^{3 / 2},} & \Delta Z(t) \geq 0, \\ 0, & \Delta Z(t)<0,\end{cases}
$$

where $G$ is the wheel-rail contact constant and $\Delta Z(t)$ is the elastic compression deformation between the wheel and rail.

The elastic compression between wheel and rail is determined by the displacement of wheel and rail at the wheelrail contact point, expressed as

$$
\Delta Z(t)=y_{w i}(t)-y_{\mathrm{r}}\left(x_{w i}, t\right)-y_{0}(t), \quad i=1 \sim 4,
$$

where $y_{w i}$ is the displacement of the wheel; $y_{\mathrm{r}}$ is the displacement of the rail; and $y_{0}$ is the track irregularity which is the main excitation of vehicle-track coupling system. The power spectral density of ballastless track irregularities of China high-speed railway [15] is as follows:

$$
S(f)= \begin{cases}1.0544 \times 10^{-5} \times f^{-3.3891}, & f \leq 0.0187, \\ 3.5588 \times 10^{-3} \times f^{-1.9271}, & 0.0187<f \leq 0.0474, \\ 1.9784 \times 10^{-3} \times f^{-1.3643}, & 0.0474<f \leq 0.1533, \\ 3.9488 \times 10^{-3} \times f^{-3.4516}, & f>0.1555,\end{cases}
$$

where $f$ is the spatial frequency.

The random track irregularities in spatial domain $y_{\text {irr }}$ can be calculated with IFFT.

The dynamic equation of the vehicle-track coupling system is obtained by combining the vehicle vibration equation with the track vibration equation, which is expressed as 


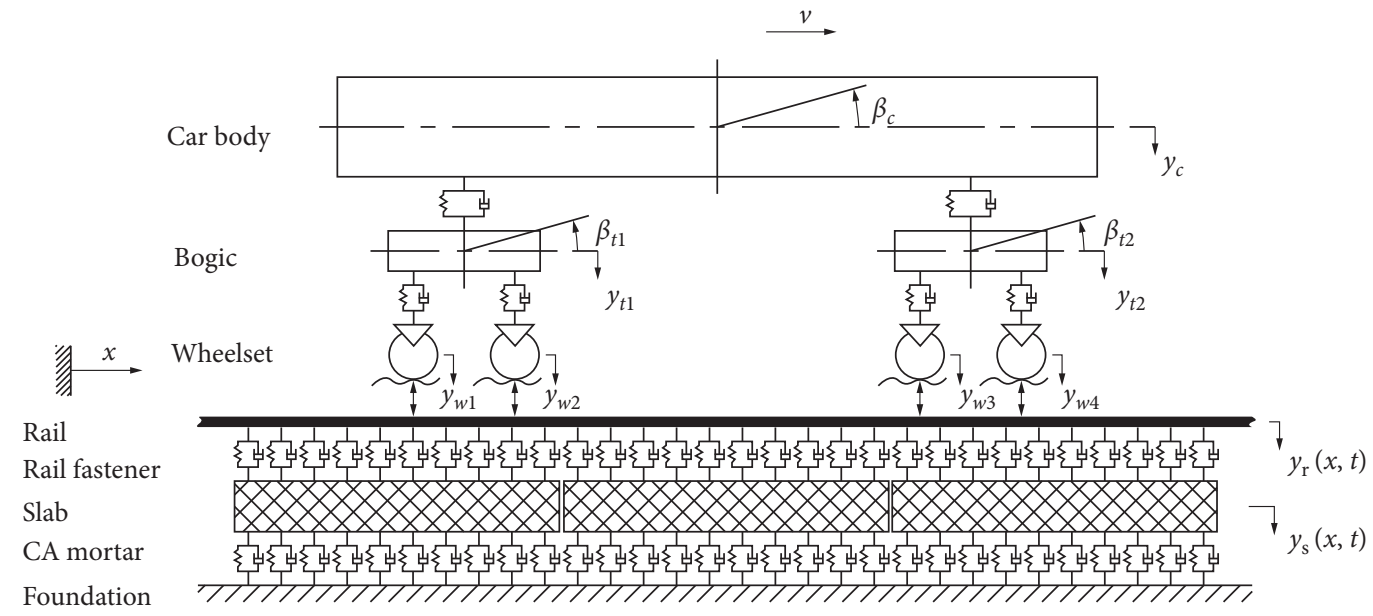

FIGURE 1: The vehicle-track system model of high-speed railway.

TAble 1: Parameters for Chinese high-speed train CRH3 [13].

\begin{tabular}{lcc}
\hline Parameter & Value & Unit \\
\hline Mass of car body & 40000 & $\mathrm{~kg}$ \\
Mass of bogie & 3200 & $\mathrm{~kg}$ \\
Mass of wheelset & 2400 & $\mathrm{~kg}$ \\
Pitch inertia of car body & 547000 & $\mathrm{~kg} \cdot \mathrm{m}^{2}$ \\
Pitch inertia of bogie & 6800 & $\mathrm{~kg} \cdot \mathrm{m}^{2}$ \\
Stiffness of primary suspension system & $2.08 \times 10^{6}$ & $\mathrm{~N} / \mathrm{m}$ \\
Stiffness of secondary suspension system & $8 \times 10^{5}$ & $\mathrm{~N} / \mathrm{m}$ \\
Damping of primary suspension system & $1 \times 10^{5}$ & $\mathrm{~N} \cdot \mathrm{s} / \mathrm{m}$ \\
Damping of secondary suspension system & $1.2 \times 10^{5}$ & $\mathrm{~N} \cdot \mathrm{s} / \mathrm{m}$ \\
Semilongitudinal distance between bogies & 8.6875 & $\mathrm{~m}$ \\
Semilongitudinal distance between & 1.25 & $\mathrm{~m}$ \\
wheelsets in bogie & 0.46 & $\mathrm{~m}$ \\
Radius of wheel & &
\end{tabular}

TABle 2: Parameters of the CRTS II slab track [13].

\begin{tabular}{lcc}
\hline Parameter & Value & Unit \\
\hline Elastic modulus of rail & $2.1 \times 10^{11}$ & $\mathrm{~N} / \mathrm{m}^{2}$ \\
Inertia of rail & $3.217 \times 10^{-5}$ & $\mathrm{~m}^{4}$ \\
Mass of rail & 60 & $\mathrm{~kg} / \mathrm{m}$ \\
Stiffness of rail fastener & $6 \times 10^{7}$ & $\mathrm{~N} / \mathrm{m}$ \\
Damping of rail fastener & $4.77 \times 10^{4}$ & $\mathrm{~N} \cdot \mathrm{s} / \mathrm{m}$ \\
Elastic modulus of slab & $3.9 \times 10^{10}$ & $\mathrm{~N} / \mathrm{m}^{2}$ \\
Inertia of slab & $8.5 \times 10^{-5}$ & $\mathrm{~m}$ \\
Mass of slab & 1275 & $\mathrm{~kg} / \mathrm{m}$ \\
Length of single slab & 6.5 & $\mathrm{~m}$ \\
Stiffness of CA mortar & $9 \times 10^{8}$ & $\mathrm{~N} / \mathrm{m}$ \\
Damping of CA mortar & $8.3 \times 10^{4}$ & $\mathrm{~N} \cdot \mathrm{s} / \mathrm{m}$ \\
\hline
\end{tabular}

$$
[M]\{A\}+[C]\{V\}+[K]\{X\}=\{P\},
$$

where $[M],[C]$, and $[K]$ are the mass, damping, and stiffness matrices of the vehicle-track coupling model, respectively; $\{A\},\{V\}$, and $\{X\}$ are the acceleration, velocity, and displacement vectors of the coupling model, respectively; and $\{P\}$ is the load vector of the coupling model.

Vehicle-track coupling model is a system of nonlinear differential equations, which can be solved by the numerical integration method.
2.4. Rail Corrugation Model. Rail corrugation is a kind of harmonic irregularity, which is expressed by a cosine function:

$$
y_{\text {cor }}(t)=\frac{1}{2} a\left[1-\cos \left(\frac{2 \pi v t}{\lambda}\right)\right], \quad\left(0 \leq t \leq \frac{L}{v}\right),
$$

where $a$ is the depth of rail corrugation; $\lambda$ is the wavelength of rail corrugation; $v$ is the train speed; and $L$ is the length of rail corrugation.

In this paper, a 130-meter track is simulated with a 10meter rail corrugation at the middle position from $60^{\circ} \mathrm{m}$ to $70^{\circ} \mathrm{m}$, of which the wavelength is from $100 \mathrm{~mm}$ to $150 \mathrm{~mm}$ and the depth is from $0.01 \mathrm{~mm}$ to $0.1 \mathrm{~mm}$. Figure 2 shows a section of rail corrugation, of which the wavelength is $150 \mathrm{~mm}$ and the depth is $0.01 \mathrm{~mm}$.

Therefore, the integrated track irregularity of the vehicletrack system can be expressed as

$$
y_{0}(t)=y_{\text {irr }}(t)+y_{\text {cor }}(t)
$$

Obviously, rail corrugation will influence the vibration response of wheels through wheel-rail interaction. Rail corrugation is a kind of short-wavelength irregularity, while the wavelength of random track irregularity is much longer. Therefore, high-frequency vibration will appear in the vibration response of wheels if rail corrugation exists, and the main frequency of high-frequency band matches the wavelength of rail corrugation. This is the basic principle of detecting rail corrugation using wheel dynamic responses.

2.5. Model Validation. It is necessary to validate the model accuracy because wheel responses used in the following detection algorithm are acquired from the model. Different conditions with different wavelength and depth of rail corrugation are simulated, and the results are compared with Wang's study [16]. The effect of rail corrugation wavelength on wheel-rail force is shown in Figure 3, in which the depth of rail corrugation is $0.1 \mathrm{~mm}$ and the train speed is $300 \mathrm{~km} / \mathrm{h}$. The results show that the influence of wavelength on wheel-rail force is nonlinear, and the maximum wheelrail force is at $120 \mathrm{~mm}$ wavelength. Sensitive wavelength is 


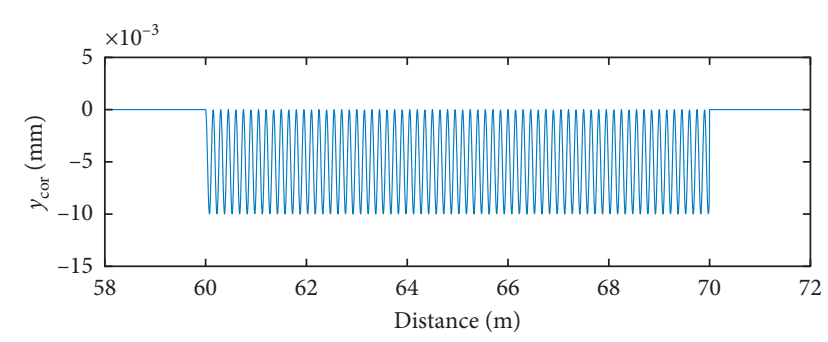

FIgURE 2: Rail corrugation.

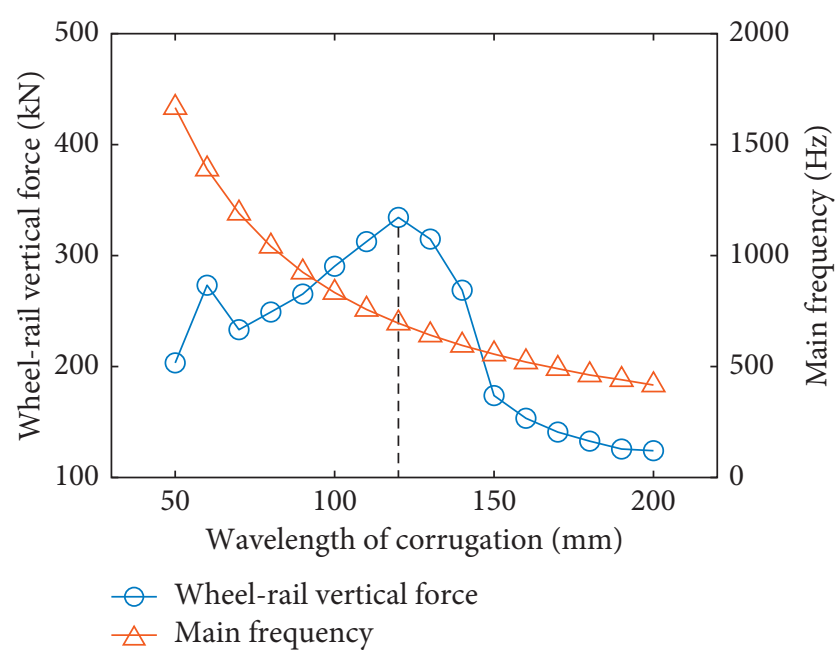

FIGURE 3: Effect of rail corrugation wavelength on wheel-rail interaction.

the wavelength when rail corrugation has the greatest effect on wheel-rail interaction. The sensitive wavelength of the simulation model is $120 \mathrm{~mm}$. In addition, the main frequency of wheel-rail force is related to the wavelength and decreases with the increase of wavelength. The effect of rail corrugation depth on maximum wheel-rail force and rail vibration acceleration is shown in Figure 4. The wavelength of rail corrugation is determined to be $100 \mathrm{~mm}$, and the train runs at $300 \mathrm{~km} / \mathrm{h}$. With the increase of rail corrugation depth, the values of wheel-rail force and rail vibration acceleration gradually increase. The simulation results show good consistence with the conclusion of Wang.

\section{Detection Method}

A detection method for rail corrugation is proposed, by which the wavelength can be estimated through analyzing main frequency of wheel vibration responses based on EEMD, and the depth can be classified with bispectrum features and SVM. The detection flow chart is shown in Figure 5. LIBSVM [17] toolbox and particle swarm optimization (PSO) are used to optimize the parameters of SVM.

3.1. Wavelength Estimation. The process of wavelength estimation can be described as 4 steps:

(1) Decompose wheel acceleration signal using EEMD method.

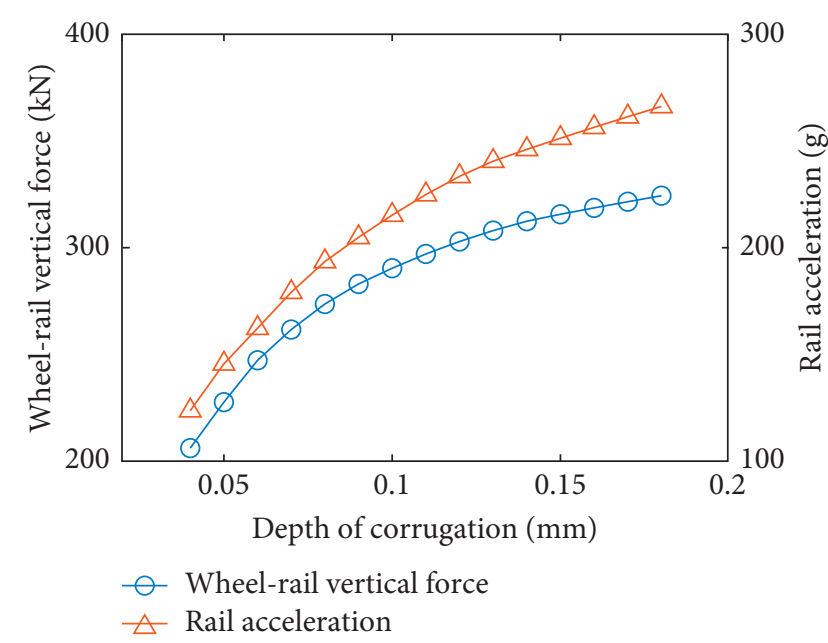

FIGURE 4: Effect of rail corrugation depth on wheel-rail interaction.

(2) Eliminate the false intrinsic modal functions (IMFs) according to the correlation analysis between the IMFs and the original signal.

(3) Select IMFs with high-frequency components and obtain their main frequency using FFT.

(4) Estimate the wavelength of rail corrugation based on main frequency and train speed.

3.1.1. Background. Huang et al. [18] defined the signal satisfying the following two conditions as intrinsic modal function (IMF): (1) the number of extreme points and zero-crossing points is equal or different by one; (2) the mean value of the upper envelope formed by the local maximum points and the lower envelope formed by the local minimum points is zero.

The EMD process for signal $x(t)$ is as follows:

(1) Find all local maximum points and local minimum points of the signal $x(t)$.

(2) Fit the upper and lower envelope and obtain the average $m(t)$ of the upper and lower envelope and then calculate

$$
h(t)=x(t)-m(t) .
$$

(3) If $h(t)$ satisfies the above two conditions, then $h(t)$ is an IMF, denoted as $c(t)$; otherwise, $h(t)$ is treated as the original signal; repeat the above two steps.

(4) Calculate the residual signal

$$
r(t)=x(t)-c(t)
$$

(5) Regard $r(t)$ as the original data and repeat the above steps until the residual signal is a monotone function.

(6) The original signal $x(t)$ can be expressed as the sum of all IMFs and residual signal $r(t)$ :

$$
x(t)=\sum_{i=1}^{n} c_{i}(t)+r(t) .
$$




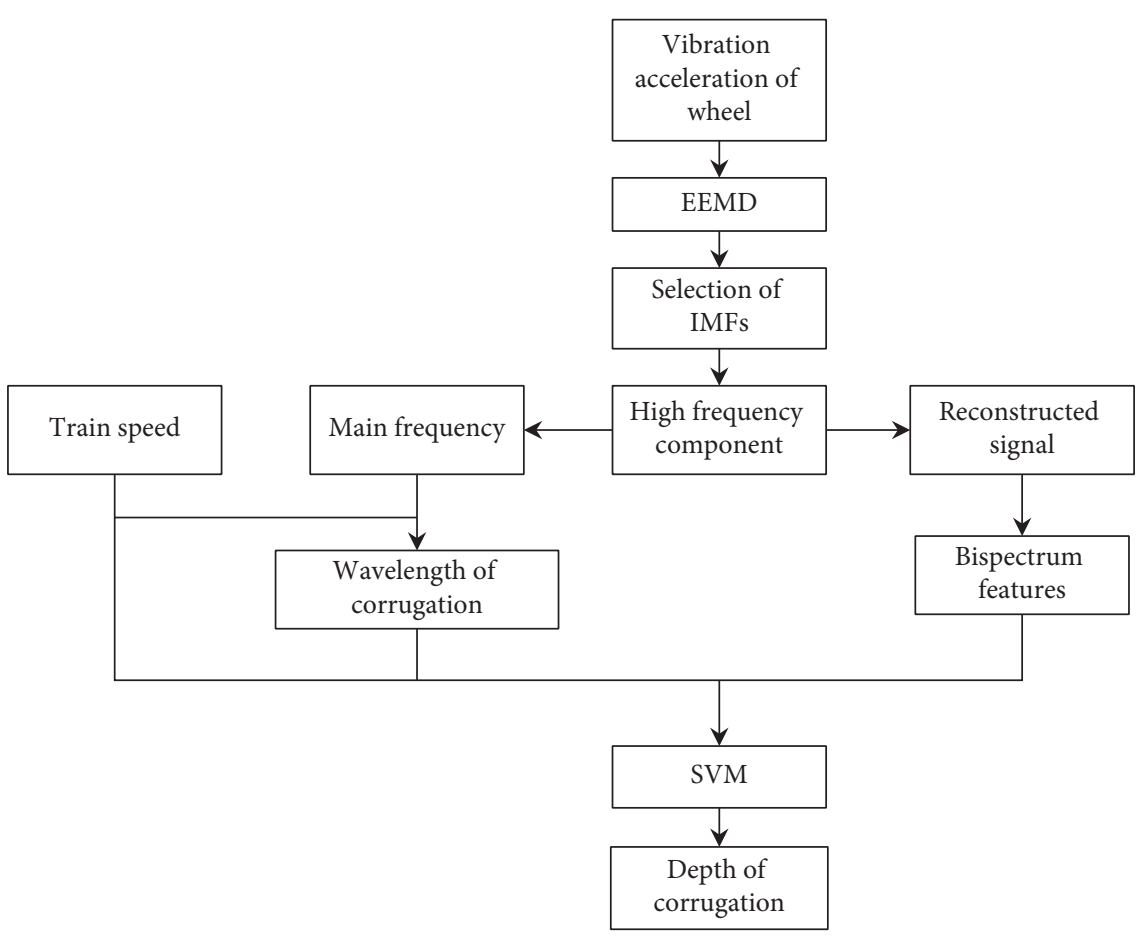

FIgURE 5: Rail corrugation detection method.

The orthogonality of IMFs is used to evaluate the decomposition results. The overall index of orthogonality is defined as

$$
\mathrm{IO}=\sum_{t=0}^{T}\left(\frac{\sum_{j=1}^{n+1} \sum_{k=1}^{n+1} c_{j}(t) c_{k}(t)}{x^{2}(t)}\right), \quad(j \neq k) .
$$

The mode mixing problem occurs when the signal is analyzed by IMF sifting method because there are multiple frequency components in an IMF. To avoid this problem, $\mathrm{Wu}$ and Huang [19] proposed EEMD based on noiseassisted data analysis method.

The EEMD process for signal $x(t)$ is as follows:

(1) Add a white noise with amplitude $\alpha$ to the signal $x(t)$.

(2) The signal with noise is analyzed by EMD.

(3) Repeat the above steps $N$ times and average the results of EMD.

The difference between the input signal and the corresponding IMF is called the final standard deviation of error, which is expressed by $e$. The added white noise satisfies the following rule [19]:

$$
e=\frac{\alpha}{\sqrt{N}}
$$

where $\alpha$ is the amplitude of the added white noise and $N$ is the number of ensemble members.

3.1.2. Selection of EEMD Key Parameters. If the amplitude of the white noise is too small, the mixing of the modes cannot be weakened. On the contrary, the final standard deviation of error will be large. If the number of ensemble members is too small, the influence of added white noise cannot be eliminated; in contrast, the calculation cost will be increased. Therefore, it is very important to select suitable amplitude of the white noise and number of ensemble members when EEMD is employed to analyze signals. The amplitude of white noise is defined as

$$
\alpha=k \cdot \sigma
$$

where $\sigma$ is the standard deviation of the signal and $k$ is a coefficient.

The purpose of added white noise is to improve the distribution of extreme points of signal. The extreme point distribution index is defined as

$$
\mathrm{SI}=\sqrt{S_{1}^{2}+S_{2}^{2}+S_{3}^{2}+S_{4}^{2}},
$$

where $S_{1}$ is the standard deviation of amplitude interval of maximum points; $S_{2}$ is the standard deviation of coordinate interval of maximum points; $S_{3}$ is the standard deviation of amplitude interval of minimum points; and $S_{4}$ is the standard deviation of coordinate interval of minimum points.

The vibration acceleration of wheel with the condition of 10 -meter rail corrugation is shown in Figure 6. White noise with different amplitudes is added to the signal, and the extreme point distribution index SI is calculated. It can be seen from Figure 7 that the extreme point distribution index SI tends to be stable when the amplitude of white noise increases to a certain value.

In this paper, the extreme point distribution index SI is used to determine the optimal range of white noise amplitude. Then, the added white noise amplitude $\alpha$ and the number $N$ of ensemble members are selected, respectively, according to the orthogonal coefficient IO and equation (11). The parameter selection algorithm of EEMD is shown in 


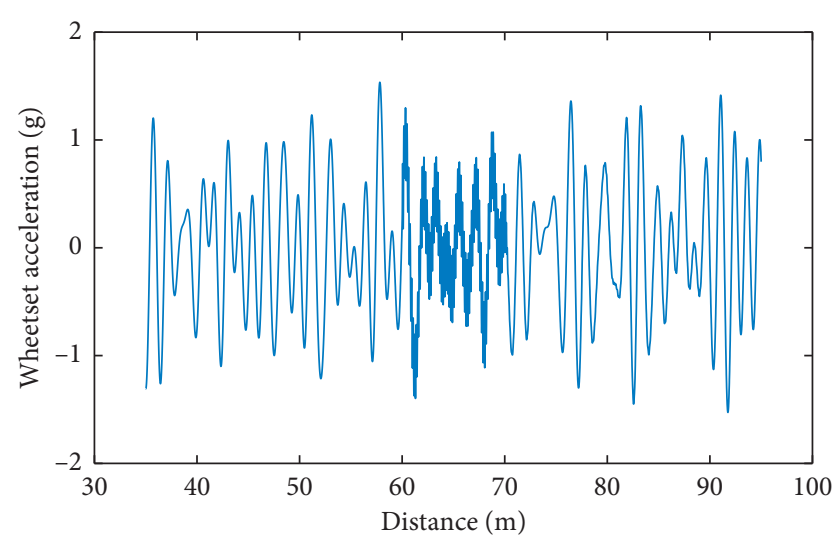

Figure 6: Vibration acceleration signal of wheel.

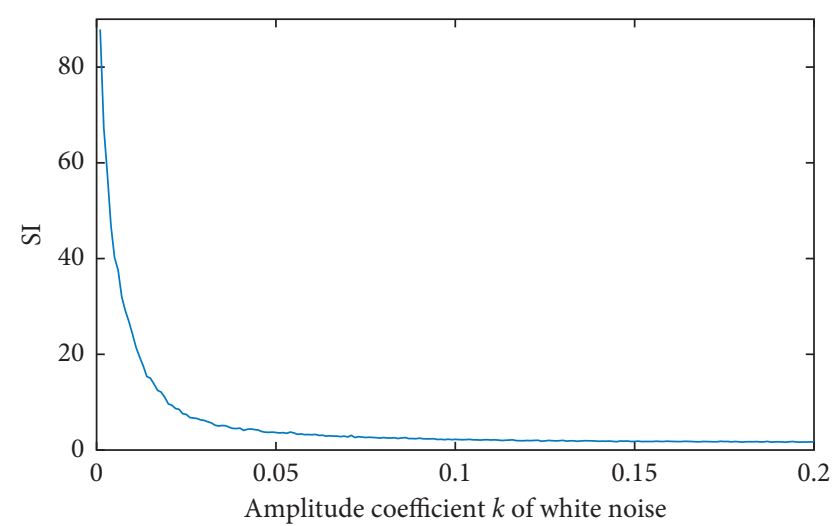

Figure 7: The extreme point distribution index SI.

Figure 8. Firstly, the optimum range of white noise amplitude is determined by the stability value of SI. In order to ensure that the amplitude of white noise can improve the distribution of signal extreme points, the minimum value of $k$ is 0.001 . The maximum value of $k$ is set to be 0.01 so that the optimization range is not too small. In order to select the appropriate amplitude of white noise, it is necessary to determine the number of ensemble members in advance. The number $N$ of ensemble members should not be too large; otherwise, the calculation time is very long. If $N$ is too small, EEMD will be invalid. After many trials, $N$ is initially set to be 10 . EEMD analyses of the signal are carried out in the optimal range of white noise amplitude, and the decomposition results are evaluated by the orthogonal coefficients. The white noise amplitude corresponding to the optimal decomposition result is the best white noise amplitude $\alpha$. In this paper, the error less than $1 \%$ can be acceptable. The final standard deviation of error is set to be 0.01 . Then, the best $N$ is determined according to the rules of the final standard deviation of error and the white noise amplitude. Meanwhile, the minimum value of $N$ is 10 to avoid the EEMD invalidation caused by too small $N$.

The vibration acceleration signals of wheel in Figure 6 are analyzed by EMD and EEMD, respectively. Figure 9 shows the first four IMFs after decomposition. IMF components are arranged from high frequency to low frequency, so the first

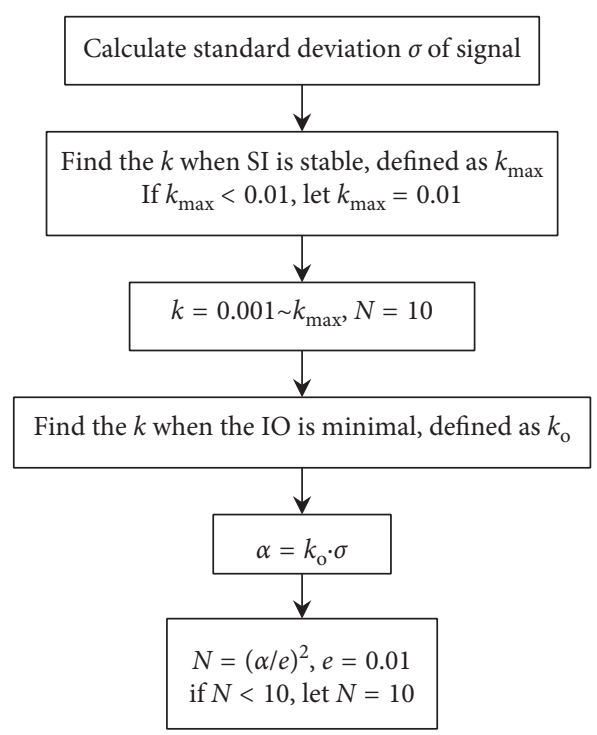

FIGURE 8: Selection algorithm of EEMD parameters.

IMF (IMF1) is the high-frequency component of the signal. It can be seen from Figure 9(a) that IMF1 of EMD analysis has low-frequency signals at other locations besides highfrequency signals caused by rail corrugation which indicates that there is mode mixing in EMD analysis. Apparently, the mode mixing will influence the detection results. In Figure 9(b), there is only the high-frequency components related with rail corrugation and no low frequency in IMF1. Therefore, EEMD analysis is an effective method to extract the part of the signal caused by rail corrugation.

3.1.3. Wavelength Calculation. After the IMFs are obtained by EEMD analysis, the IMFs are selected to eliminate the effects of noise and the random irregularity of the track. IMF selection and signal reconstruction algorithm are shown in Figure 10. The false components are eliminated by correlation analysis, and the high-frequency components are reconstructed into a high-frequency signal which is caused by rail corrugation.

Estimation of wavelength of rail corrugation by main frequency of the reconstructed signal $y_{\mathrm{r}}$ is expressed as

$$
\lambda=\frac{v}{f_{\mathrm{m}}},
$$

where $v$ is train speed and $f_{\mathrm{m}}$ is the main frequency of the reconstructed signal, which can be obtained by FFT.

3.2. Features Extraction of Corrugation Depth. The vibration acceleration signals of wheel under rail corrugation are nonlinear, nonstationary, and non-Gaussian. Higher-order spectra are useful in analyzing nonlinearity and nonGaussianity of the signal as it provides high noise immunity [20]. The frequency domain representation of thirdorder cumulants of signals is called bispectrum, which is expressed as

$$
B\left(f_{1}, f_{2}\right)=E\left[X\left(f_{1}\right) X\left(f_{2}\right) X^{*}\left(f_{1}+f_{2}\right)\right],
$$



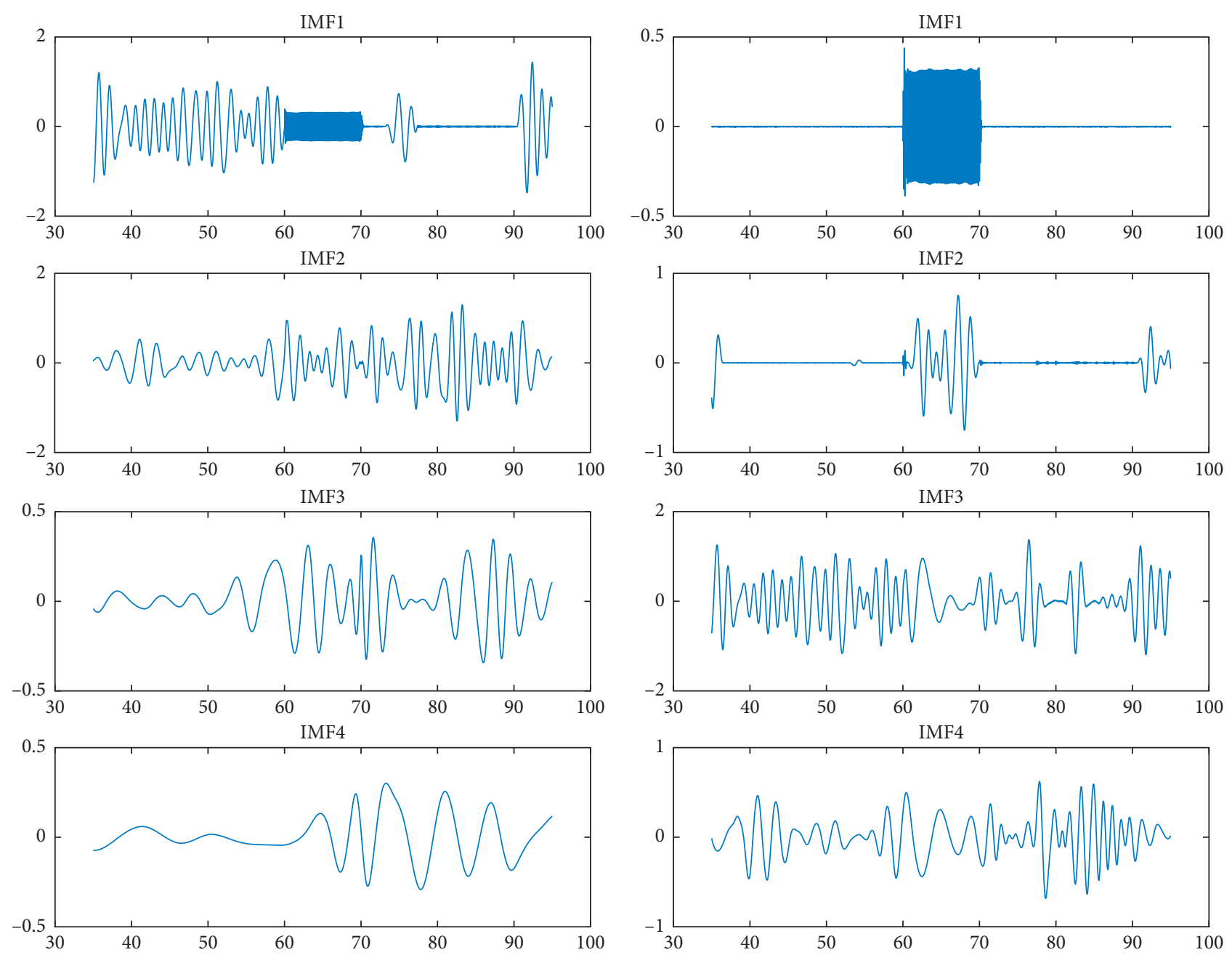

(a)

(b)

FIgUre 9: The first four IMFs of the signal. (a) EMD. (b) EEMD.

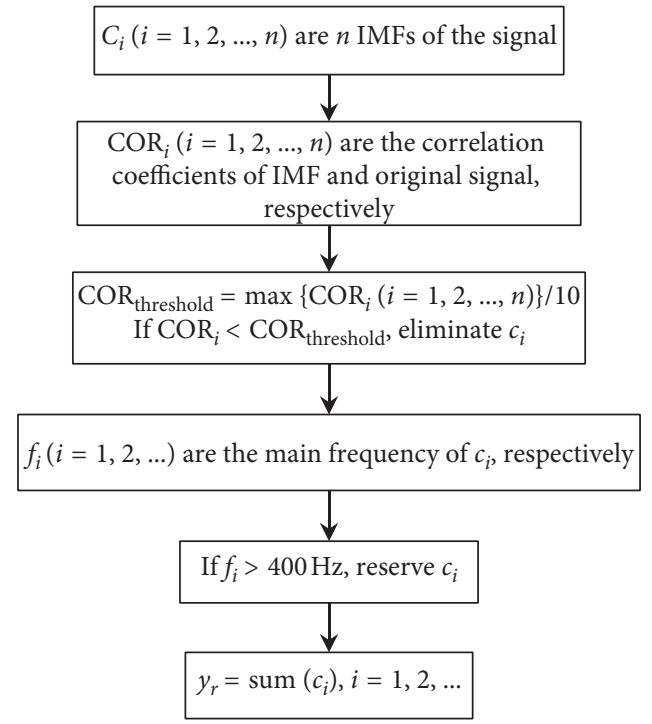

FIGURE 10: IMFs selection and signal reconstruction algorithm. 
where $X(f)$ is the Fourier transform of the signal; ${ }^{*}$ denotes complex conjugate; $E[$.] denotes the expectation operation; and the frequency $f$ may be normalized by the Nyquist frequency to be between 0 and 1 .

The discrete bispectrum matrix $B$ is obtained by the high order spectral analysis of the reconstructed signal $y_{\mathrm{r}}(t)$. The size of the bispectrum matrix $B$ is $Q \times Q$. In order to recognize the depth of rail corrugation easily, bispectrum features need to be extracted.

Three amplitude features of bispectrum [21]:

$$
\begin{aligned}
& \mathrm{Amp}_{1}=\frac{1}{\mathrm{Q}^{2}} \sum_{\Omega}|B(i, j)|, \\
& \mathrm{Amp}_{2}=\sum_{\Omega} \log (|B(i, j)|), \\
& \mathrm{Amp}_{3}=\sum_{i=1}^{Q} \log (|B(i, i)|) .
\end{aligned}
$$

Three moment features of bispectrum [22]:

$$
\begin{aligned}
& \operatorname{Mom}_{1}=\sum_{i=1}^{Q} i \cdot \log (|B(i, i)|), \\
& \operatorname{Mom}_{2}=\sum_{i=1}^{Q}(i-M)^{2} \cdot \log (|B(i, i)|), \\
& \operatorname{Mom}_{3}=\sum_{\Omega} \sqrt{i^{2}+j^{2}} \cdot|B(i, j)| .
\end{aligned}
$$

Three entropy features of bispectrum [23]:

$$
\text { Ent }_{1}=-\sum_{\Omega} p_{1}(i, j) \cdot \log \left(p_{1}(i, j)\right)
$$

where $p_{1}(i, j)=|B(i, j)| / \sum_{\Omega}|B(i, j)|$.

$$
\mathrm{Ent}_{2}=-\sum_{\Omega} p_{2}(i, j) \cdot \log \left(p_{2}(i, j)\right),
$$

where $p_{2}(i, j)=|B(i, j)|^{2} / \sum_{\Omega}|B(i, j)|^{2}$.

$$
\mathrm{Ent}_{3}=-\sum_{\Omega} p_{3}(i, j) \cdot \log \left(p_{3}(i, j)\right),
$$

where $p_{3}(i, j)=|B(i, j)|^{3} / \sum_{\Omega}|B(i, j)|^{3}$.

The above nine bispectrum features have different amplitudes at different rail corrugation depths, as shown in Figure 11. Three entropy features of bispectrum change nonlinearly with the increase of rail corrugation depth, while the other features of bispectrum increase with the increase of rail corrugation depth. The bispectrum features can well reflect the depth of rail corrugation.

The train speed and the wavelength of the rail corrugation also affect the vibration response of the wheel. Therefore, the train speed $v$ and the estimated wavelength $\lambda$ are also taken as the feature parameters. The extracted features are constructed into a features vector and classified using the SVM model.

\section{Detection Result}

4.1. Data Preparation. In the simulation model, the train speeds are $250 \mathrm{~km} / \mathrm{h}$ to $350 \mathrm{~km} / \mathrm{h}$, the wavelengths of rail

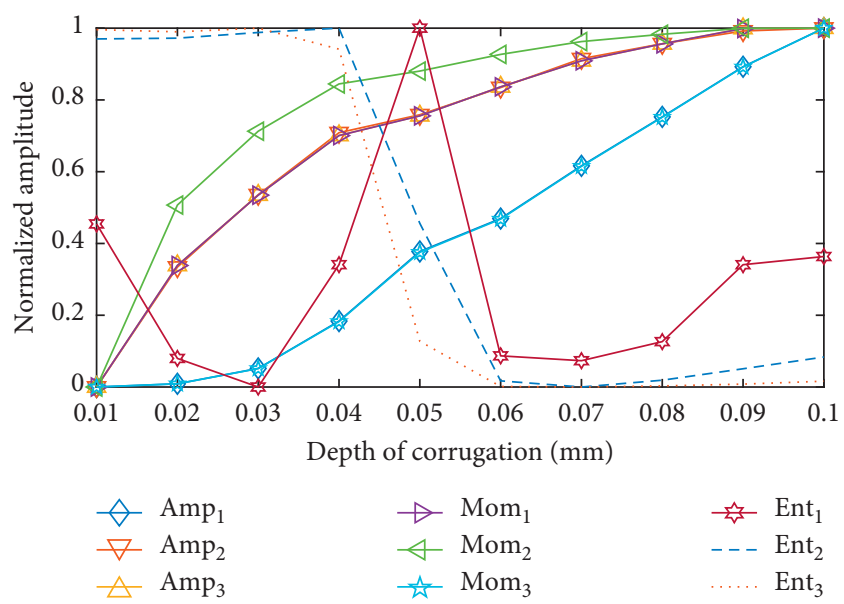

FIgURE 11: Bispectrum features at different depths of corrugation (train speed is $250 \mathrm{~km} / \mathrm{h}$ and wavelength is $100 \mathrm{~mm}$ ).

corrugation are $100 \mathrm{~mm}$ to $150 \mathrm{~mm}$, and the depths of rail corrugation are $0.01 \mathrm{~mm}$ to $0.1 \mathrm{~mm}$. There are 660 signals. After repeated 10 simulations, 6600 sets of vibration acceleration signals of wheel are obtained. The signal length is $60 \mathrm{~m}$ including $25 \mathrm{~m}$ before the wheel enters the rail corrugation and $25 \mathrm{~m}$ after it leaves the rail corrugation.

In order to verify the antinoise ability of the detection method, a Gaussian noise signal is added to the wheel acceleration signal to simulate the measurement noise.

$$
x_{\text {measurement }}=x_{\text {simulation }}+E_{p} \times\{N\} \times \operatorname{var}\left(x_{\text {simulation }}\right) \text {, }
$$

where $E_{p}$ is the noise level; $\{N\}$ is a standard normal distribution vector with zero mean and unit standard deviation; and $\operatorname{var}($.$) denotes the standard deviation of signal.$

4.2. Wavelength Estimation of Rail Corrugation. The estimation results of rail corrugation wavelength are shown in Figure 12. It can be seen from Figure 12 that the wavelength of rail corrugation can be estimated at different corrugation depths and train speeds, and the noise has no effect on the estimation algorithm.

The relative error between the estimated value of wavelength and the true value of wavelength is defined as:

$$
\text { error }=\frac{1}{n} \sum_{i=1}^{n} \frac{\left|\lambda_{i}^{\text {estimation }}-\lambda_{i}^{\text {true }}\right|}{\lambda_{i}^{\text {true }}},
$$

where $n$ is the number of data samples.

In order to analyze the influence of corrugation depth on wavelength estimation, depths of $0.01 \mathrm{~mm}, 0.05 \mathrm{~mm}$, and $0.1 \mathrm{~mm}$ rail corrugation are selected, respectively. The wavelength estimation results with $0 \%, 1 \%, 3 \%$, and $5 \%$ noise levels are shown in Table 3 . The wavelength estimation error of rail wavelength is almost unchanged under different depths, and the maximum value of wavelength estimation error is not more than $0.2 \%$. The wavelength estimation errors are very small, which shows that the estimation of rail wavelength is completely reliable. Moreover, the simulation results show that the proposed method can estimate the 

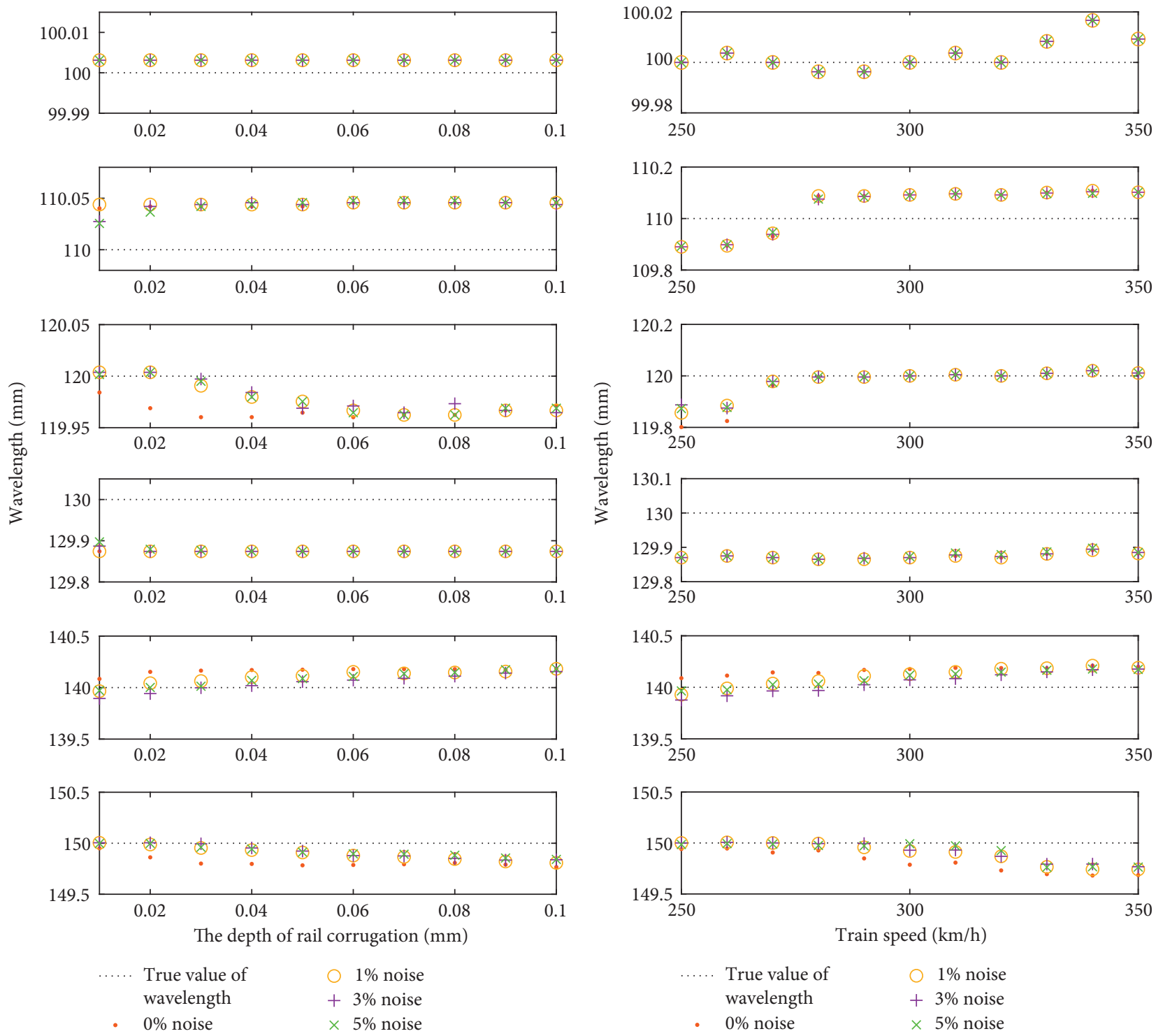

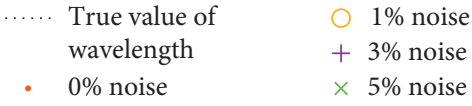

(a)

(b)

FIGURE 12: The estimation results of rail corrugation wavelength. (a) At different depths of rail corrugation. (b) At different train speeds.

TABle 3: Wavelength estimation error at different depths of rail corrugation.

\begin{tabular}{lcccccccccccc}
\hline \multirow{2}{*}{ Case } & \multicolumn{3}{c}{ Depth $0.01 \mathrm{~mm}$} & \multicolumn{3}{c}{ Depth $0.05 \mathrm{~mm}$} & \multicolumn{4}{c}{ Depth $0.1 \mathrm{~mm}$} \\
& Nil & $1 \%$ & $3 \%$ & $5 \%$ & Nil & $1 \%$ & $3 \%$ & $5 \%$ & Nil & $1 \%$ & $3 \%$ & $5 \%$ \\
\hline $100 \mathrm{~mm}$ & 0.0045 & 0.0045 & 0.0045 & 0.0045 & 0.0045 & 0.0045 & 0.0045 & 0.0045 & 0.0045 & 0.0045 & 0.0045 & 0.0045 \\
$110 \mathrm{~mm}$ & 0.0900 & 0.0897 & 0.0908 & 0.0910 & 0.0902 & 0.0900 & 0.0900 & 0.0899 & 0.0899 & 0.0899 & 0.0900 & 0.0899 \\
$120 \mathrm{~mm}$ & 0.0205 & 0.0045 & 0.0045 & 0.0063 & 0.0367 & 0.0276 & 0.0330 & 0.0275 & 0.0313 & 0.0349 & 0.0367 & 0.0330 \\
$130 \mathrm{~mm}$ & 0.0968 & 0.0968 & 0.0980 & 0.0994 & 0.0968 & 0.0968 & 0.0968 & 0.0968 & 0.0968 & 0.0968 & 0.0968 & 0.0968 \\
$140 \mathrm{~mm}$ & 0.1252 & 0.1124 & 0.1001 & 0.1100 & 0.1347 & 0.1286 & 0.1230 & 0.1260 & 0.1360 & 0.1357 & 0.1329 & 0.1358 \\
$150 \mathrm{~mm}$ & 0.0376 & 0.0045 & 0.0045 & 0.0087 & 0.1453 & 0.0623 & 0.0543 & 0.0601 & 0.1563 & 0.1293 & 0.1091 & 0.1068 \\
\hline
\end{tabular}

wavelength well under the conditions of different depths and measurement noises.

The train speeds are $250 \mathrm{~km} / \mathrm{h}, 300 \mathrm{~km} / \mathrm{h}$, and $350 \mathrm{~km} / \mathrm{h}$, and the wavelength of rail corrugation is estimated, respectively. The wavelength estimation results with $0 \%, 1 \%$, $3 \%$, and $5 \%$ noise levels are shown in Table 4 . The wavelength estimation error of rail wavelength is almost unchanged at different depths, and the maximum value of wavelength estimation error is not more than $0.25 \%$. The wavelength estimation error is also very small, which indicates that the wavelength estimation effect of rail corrugation is very good. Meanwhile, the simulation results 
TABLE 4: Wavelength estimation error at different train speeds.

\begin{tabular}{lcccccccccccc}
\hline \multirow{2}{*}{ Case } & \multicolumn{3}{c}{ Train speed $250 \mathrm{~km} / \mathrm{h}$} & \multicolumn{3}{c}{ Train speed $300 \mathrm{~km} / \mathrm{h}$} & \multicolumn{4}{c}{ Train speed $350 \mathrm{~km} / \mathrm{h}$} \\
& Nil & $1 \%$ & $3 \%$ & $5 \%$ & Nil & $1 \%$ & $3 \%$ & $5 \%$ & Nil & $1 \%$ & $3 \%$ & $5 \%$ \\
\hline $100 \mathrm{~mm}$ & 0 & 0 & 0 & 0 & 0 & 0 & 0 & 0 & 0.0093 & 0.0093 & 0.0093 & 0.0093 \\
$110 \mathrm{~mm}$ & 0.0999 & 0.0999 & 0.0999 & 0.0997 & 0.0834 & 0.0834 & 0.0834 & 0.0836 & 0.0927 & 0.0927 & 0.0927 & 0.0927 \\
$120 \mathrm{~mm}$ & 0.1657 & 0.1198 & 0.0938 & 0.1058 & 0 & 0 & 0 & 0 & 0.0093 & 0.0093 & 0.0093 & 0.0093 \\
$130 \mathrm{~mm}$ & 0.0999 & 0.0999 & 0.0999 & 0.0999 & 0.0999 & 0.0999 & 0.0999 & 0.1001 & 0.0907 & 0.0907 & 0.0910 & 0.0910 \\
$140 \mathrm{~mm}$ & 0.1234 & 0.1070 & 0.1016 & 0.1107 & 0.1325 & 0.1275 & 0.1217 & 0.1265 & 0.1428 & 0.1412 & 0.1391 & 0.1386 \\
$150 \mathrm{~mm}$ & 0.0399 & 0 & 0 & 0.0100 & 0.1421 & 0.0524 & 0.0474 & 0.0050 & 0.2124 & 0.1778 & 0.1616 & 0.1639 \\
\hline
\end{tabular}

illustrate that the proposed method can estimate the wavelength excellent under the conditions of different train speeds and measurement noises.

4.3. Depth Classification of Rail Corrugation. According to the values of depth of rail corrugations, three depth levels are divided, as shown in Table 5.

Bispectrum features, estimated wavelength, and train speed are taken as inputs of SVM and depth level is taken as SVM output. The $80 \%$ of all simulation data is used to train the SVM model, and the remaining $20 \%$ is used for testing.

The classification results of rail corrugation depth level with different levels of noise are shown in Figure 13.

The reliability of the proposed method is evaluated by the accuracy of the test results. The ratio between the number of correct classification results and the number of total test samples is defined as the detection accuracy, which can be expressed as

$$
\text { accuray }=\frac{\text { Num }_{\text {correct }}}{\text { Num }_{\text {total }}} \times 100 \% \text {. }
$$

The detection results of depth level with $0 \%, 1 \%, 3 \%$, and $5 \%$ noise levels are shown in Table 6 . The detection accuracy is more than $99 \%$, indicating that the extracted corrugation depth feature is effective. The proposed detection method has strong antinoise ability and still has high accuracy under different measurement noises.

\section{Conclusion}

Rail corrugation is a short-wavelength track irregularity excitation and accordingly causes high-frequency vibration response of wheel. A rail detection algorithm based on EEMD and bispectrum features is proposed using wheel vibration acceleration. Different frequency components of wheel vibration response are extracted with EEMD of wheel vibration acceleration signal. The parameters $\alpha$ and $N$ of EEMD are optimized using the orthogonal coefficient IO and the extreme point distribution index SI, which reduces the mode mixing and calculation time of the decomposition. The main frequency is found after EEMD to calculate the wavelength. The depth detection is regarded as a classification problem with SVM. The high-frequency signal of rail corrugation is reconstructed through the selection of IMFs, by which not only the interference of track random irregularity is avoided but also noise influence. Bispectrum features, which are extracted from the
Table 5: Definition of depth levels of rail corrugation.

\begin{tabular}{lc}
\hline Depth levels & Depths of rail corrugation $(\mathrm{mm})$ \\
\hline Level 1 & $a \leqq 0.04$ \\
Level 2 & $0.04<a \leqq 0.07$ \\
Level 3 & $a>0.07$ \\
\hline
\end{tabular}

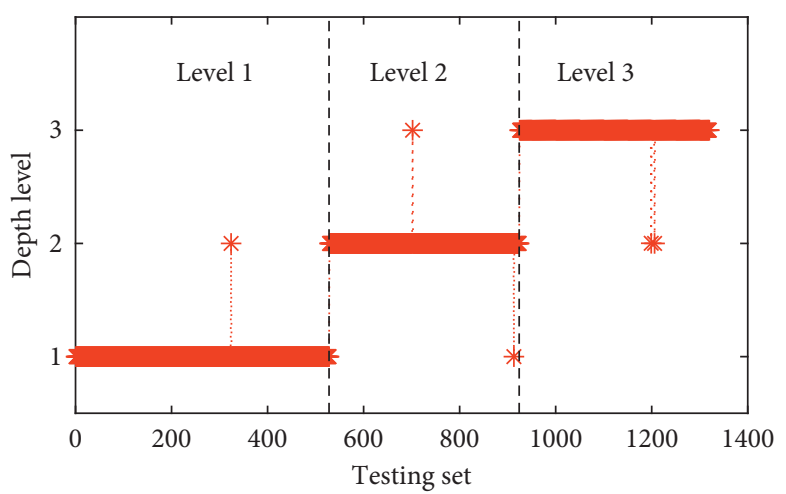

(a)

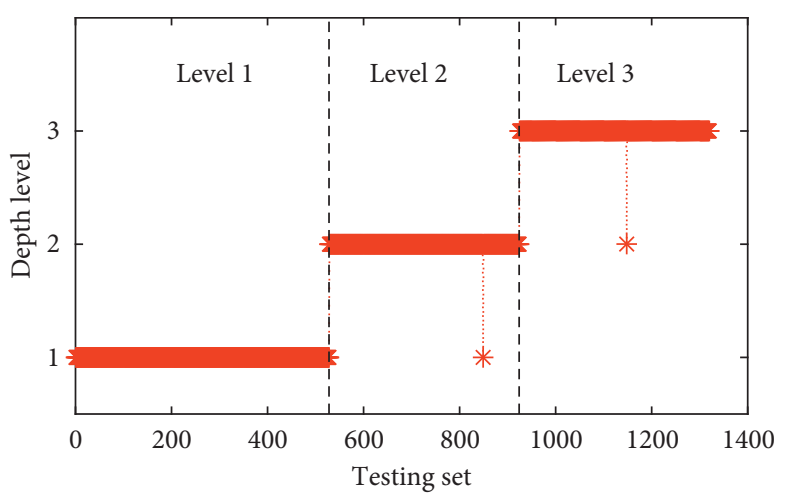

(b)

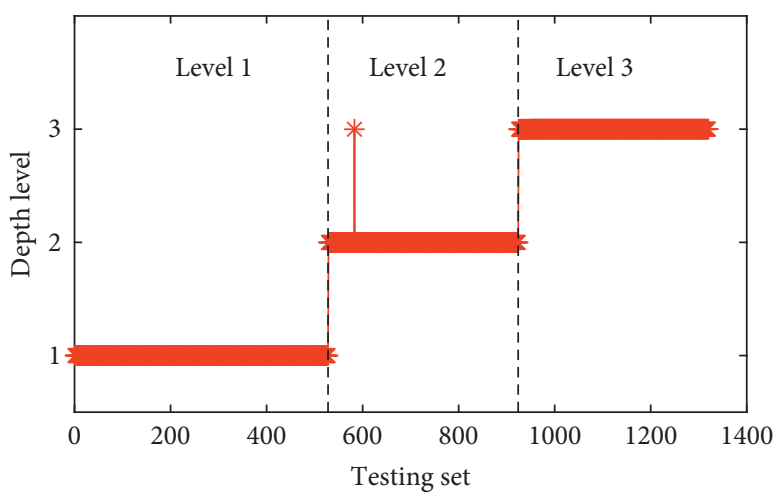

(c)

FIgURE 13: Continued. 


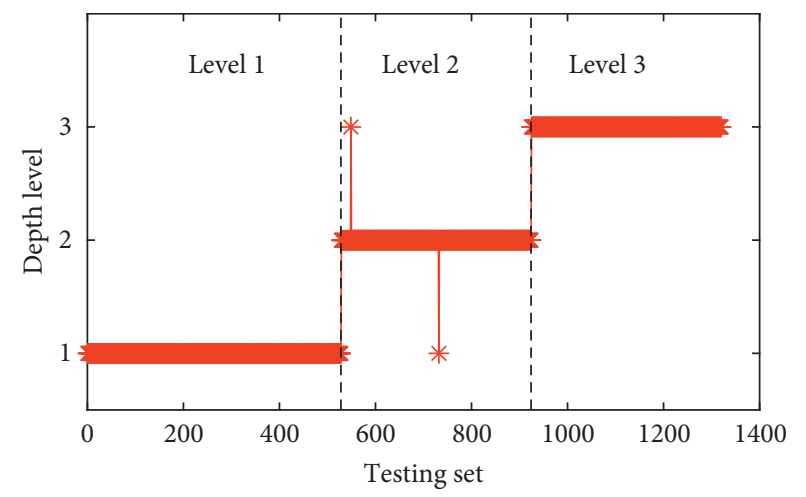

(d)

FIgURE 13: The classification results of rail corrugation depth level. (a) $0 \%$ noise. (b) $1 \%$ noise. (c) $3 \%$ noise. (d) $5 \%$ noise.

TABle 6: The accuracy of depth level classification results at different measurement noises.

\begin{tabular}{lcccc}
\hline Noise level & Nil & $1 \%$ & $3 \%$ & $5 \%$ \\
\hline Accuracy of level 1 (\%) & 99.81 & 100 & 100 & 100 \\
Accuracy of level 2 (\%) & 99.49 & 99.75 & 99.75 & 99.49 \\
Accuracy of level 3 (\%) & 99.49 & 99.75 & 100 & 100 \\
Total accuracy (\%) & 99.62 & 99.85 & 99.92 & 99.85 \\
\hline
\end{tabular}

reconstructed signal, combining with train speed and the corrugation wavelength, are input into SVM. The numerical simulation results show the proposed detection algorithm can accurately identify the existence of rail corrugation. The error between the estimated wavelength and the real value is small, and the accuracy of corrugation depth level classification is high. And the results also represent robustness under different train speeds and measurement noises. The proposed rail corrugation detection method provides a feasible scheme for the inservice vehicle test in the future.

\section{Data Availability}

The data used to support the findings of this study are included within the article.

\section{Conflicts of Interest}

The authors declare that they have no conflicts of interest.

\section{Acknowledgments}

This work was supported by the National Key Research and Development Program of China under Grant no. 2016YFB1200401.

\section{References}

[1] K. H. Oostermeijer, "Review on short pitch rail corrugation studies,” Wear, vol. 265, no. 9-10, pp. 1231-1237, 2008.

[2] Z. Q. Jiang, D. L. Si, W. Li et al., "On rail corrugation of high speed railway (in Chinese)," China Railway Science, vol. 35, no. 4, pp. 9-14, 2014.
[3] B. M. Hopkins and S. Taheri, "Track health monitoring using wavelet," in Proceedings of ASME 2010 Rail Transportation Division Fall Technical Conference, pp. 9-15, Roanoke, VA, USA, October 2010.

[4] M. Molodova, Z. Li, and R. Dollevoet, "Axle box acceleration: measurement and simulation for detection of short track defects," Wear, vol. 271, no. 1-2, pp. 349-356, 2011.

[5] W. Huang, W. Zhang, Y. Du et al., "Detection of rail corrugation based on fiber laser accelerometers," Measurement Science and Technology, vol. 24, no. 9, article 094014, 2013.

[6] S. Kaewunruen, "Monitoring of rail corrugation growth on sharp curves for track maintenance prioritisation," International Journal of Acoustics and Vibration, vol. 23, no. 1, pp. 35-43, 2018.

[7] P. Salvador, V. Naranjo, R. Insa, and P. Teixeira, "Axlebox accelerations: their acquisition and time-frequency characterisation for railway track monitoring purposes," Measurement, vol. 82, pp. 301-312, 2016.

[8] Z. Shen, Q. Wang, Y. Shen et al., "Accent extraction of emotional speech based on modified ensemble empirical mode decomposition," in Proceedings of Instrumentation and Measurement Technology Conference, Austin, TX, USA, May 2010.

[9] W. Guo and P. W. Tse, "A novel signal compression method based on optimal ensemble empirical mode decomposition for bearing vibration signals," Journal of Sound and Vibration, vol. 332, no. 2, pp. 423-441, 2013.

[10] X. Xue, J. Zhou, Y. Xu, W. Zhu, and C. Li, “An adaptively fast ensemble empirical mode decomposition method and its applications to rolling element bearing fault diagnosis," Mechanical Systems and Signal Processing, vol. 62-63, pp. 444-459, 2015.

[11] M. Kedadouche, M. Thomas, and A. Tahan, "A comparative study between empirical wavelet transforms and empirical mode decomposition methods: application to bearing defect diagnosis," Mechanical Systems and Signal Processing, vol. 81, pp. 88-107, 2016.

[12] W. Zhai and X. Sun, "A detailed model for investigating vertical interaction between railway vehicle and track," Vehicle System Dynamics, vol. 23, no. 1, pp. 603-615, 1994.

[13] X. Lei and J. Wang, "Dynamic analysis of the train and slab track coupling system with finite elements in a moving frame of reference," Journal of Vibration and Control, vol. 20, no. 9, pp. 1301-1317, 2013.

[14] W. Zhai, K. Wang, and C. Cai, "Fundamentals of vehicle-track coupled dynamics," Vehicle System Dynamics, vol. 47, no. 11, pp. 1349-1376, 2009.

[15] X. Kang, X. B. Liu, H. Y. LI et al., "PSD of ballastless track irregularities of high-speed railway (in Chinese)," Scientia Sinica Technologica, vol. 44, no. 7, pp. 687-696, 2014.

[16] K. Wang, P. Liu, W. Zhai, C. Huang, Z. Chen, and J. Gao, "Wheel/rail dynamic interaction due to excitation of rail corrugation in high-speed railway," Science China Technological Sciences, vol. 58, no. 2, pp. 226-235, 2015.

[17] C. C. Chang and C. J. Lin, "LLIBSVM: a library for support vector machines," ACM Transactions on Intelligent Systems and Technology, vol. 2, no. 3, pp. 1-27, 2011.

[18] N. E. Huang, Z. Shen, S. R. Long et al., "The empirical mode decomposition and the Hilbert spectrum for nonlinear and non-stationary time series analysis," Proceedings of the Royal Society A-Mathematical Physical and Engineering Sciences, vol. 454, no. 1971, pp. 909-995, 1998. 
[19] Z. Wu and N. E. Huang, "Ensemble empirical mode decomposition: a noise-assisted data analysis method," Advances in Adaptive Data Analysis, vol. 1, no. 1, pp. 1-41, 2009.

[20] L. W. Jian and T.-C. Lim, "Automated detection of diabetes by means of higher order spectral features obtained from heart rate signals," Journal of Medical Imaging and Health Informatics, vol. 3, no. 3, pp. 440-447, 2013.

[21] R. Yuvaraj, M. Murugappan, N. Mohamed Ibrahim et al., "Detection of emotions in Parkinson's disease using higher order spectral features from brain's electrical activity," Biomedical Signal Processing and Control, vol. 14, pp. 108-116, 2014.

[22] C.K.Y., M. Hariharan, R. Ngadiran, A. H. Adom, S. Yaacob, and K. Polat, "Hybrid BBO_PSO and higher order spectral features for emotion and stress recognition from natural speech," Applied Soft Computing, vol. 56, pp. 217-232, 2017.

[23] L. Saidi, J. Ben Ali, F. Fnaiech et al., "Application of higher order spectral features and support vector machines for bearing faults classification," ISA Transactions, vol. 54, pp. 193-206, 2015. 


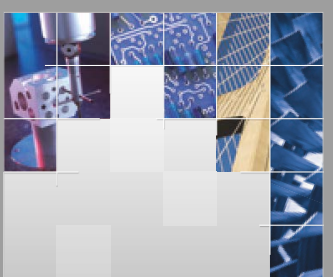

\section{Enfincering}
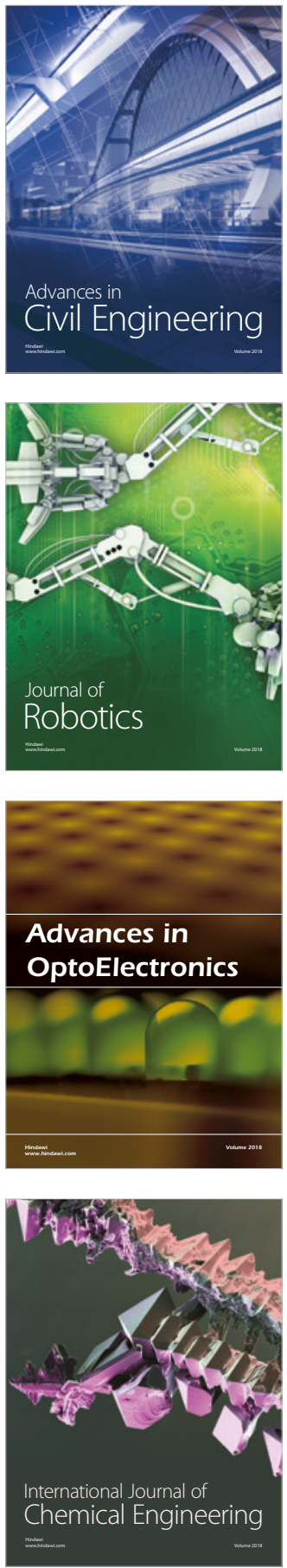

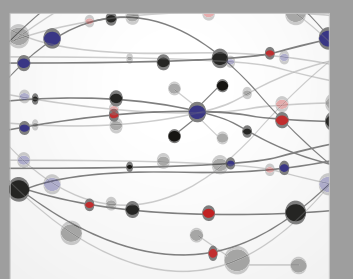

\section{Rotating \\ Machinery}

The Scientific World Journal

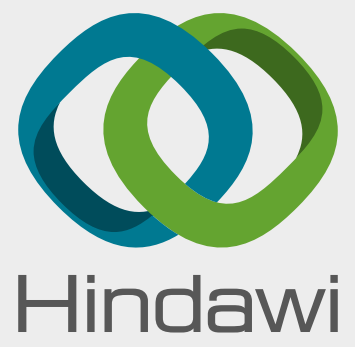

Submit your manuscripts at

www.hindawi.com
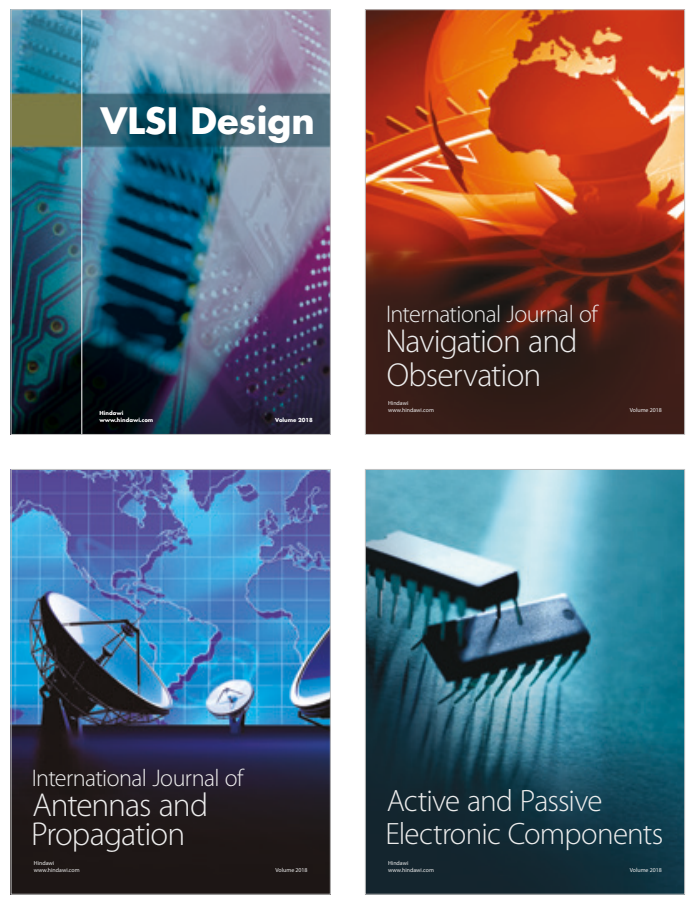
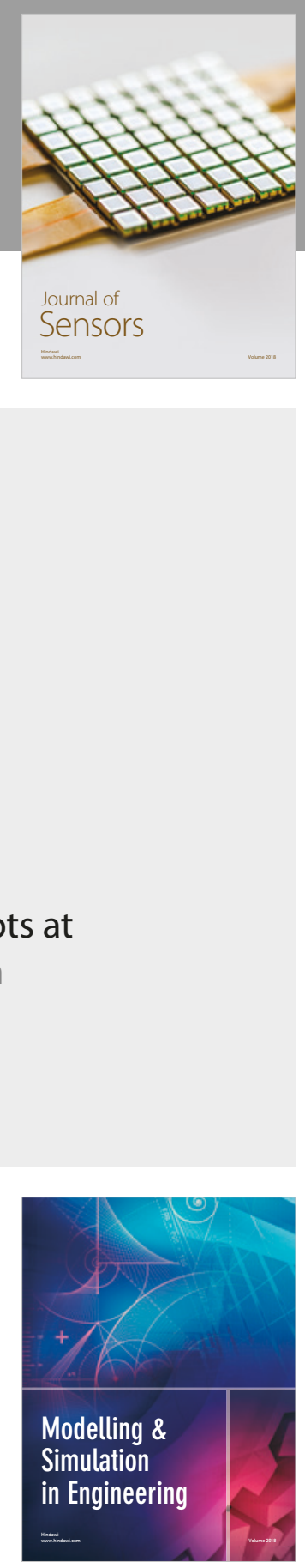

\section{Advances \\ Multimedia}
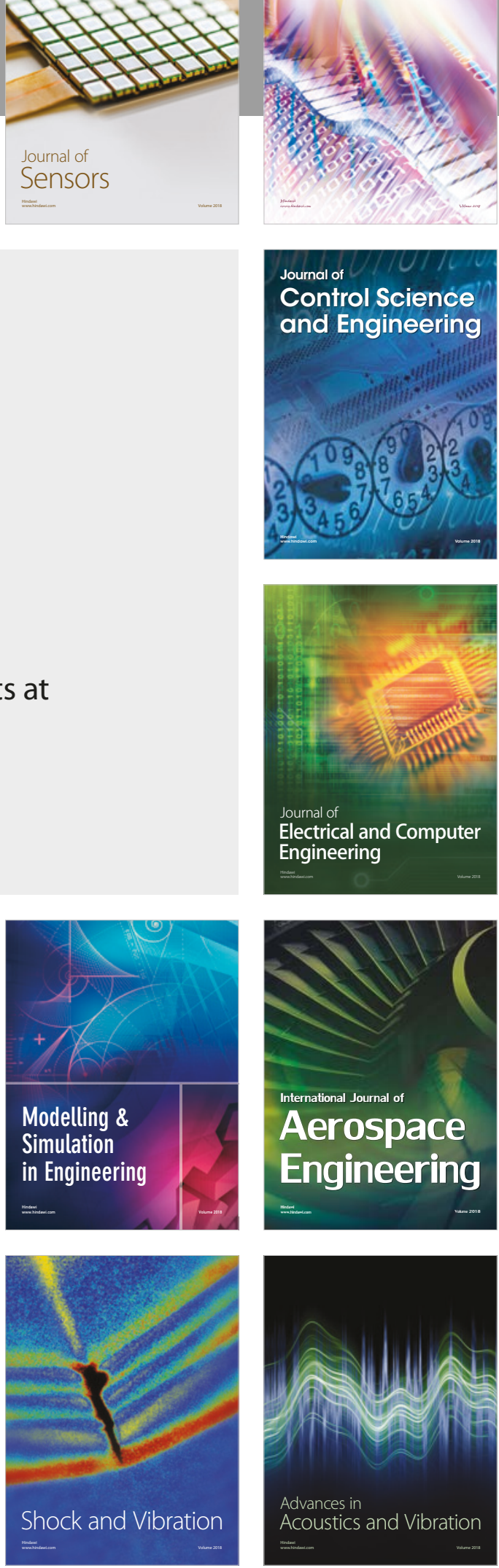